\title{
Monitoring the skin NADH changes during ischaemia and reperfusion in humans
}

\author{
Jan Niziński \\ Department of Cardiology-Intensive Therapy, \\ Poznan University of Medical Sciences, Poland \\ (DD https://orcid.org/0000-0002-5455-3845 \\ Lukasz Kamieniarz \\ University College London, London, United Kingdom \\ (iD) https://orcid.org/0000-0002-8427-9568 \\ Piotr Filberek \\ Department of Cardiology-Intensive Therapy, \\ Poznan University of Medical Sciences, Poland \\ (D) https://orcid.org/0000-0001-7575-8084

\section{Greta Sibrecht} \\ Department of Cardiology-Intensive Therapy, \\ Poznan University of Medical Sciences, Poland \\ (D) https://orcid.org/0000-0002-8905-7921 \\ Przemysław Guzik \\ Department of Cardiology-Intensive Therapy, \\ Poznan University of Medical Sciences, Poland \\ (iD) http://orcid.org/0000-0001-9052-5027 \\ Corresponding author: pguzik@ptkardio.pl
}

DOI: https://doi.org/10.20883/medical.405

Keywords: 460-nm fluorescence, ischaemia, microcirculation, mitochondria, nicotinamide adenine dinucleotide, reperfusion

Published: 2020-01-31

How to Cite: Niziński J, Kamieniarz L, Filberek P, Sibrecht G, Guzik P. Monitoring the skin NADH changes during ischaemia and reperfusion in humans. JMS [Internet]. 2020 Mar 31;89(1):e405. doi:10.20883/medical.405

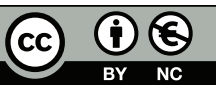

(c) 2020 by the author(s). This is an open access article distributed under the terms and conditions of the Creative Commons Attribution (CC BY-NC) licencse. Published by Poznan University of Medical Sciences

\begin{abstract}
Nicotinamide adenine dinucleotide (NADH/NAD+) is involved in many important biochemical reactions in human metabolism, including participation in energy production by mitochondria. Flow Mediated Skin Fluorescence (FMSF) is a non-invasive method to study dynamic changes in the content of the reduced form of $\mathrm{NADH}$ by measuring the optical properties of NADH related to the emission of the autofluorescent light (460 $\mathrm{nm}$ ) after an earlier excitation by ultraviolet light. This review summarises the available studies using this method to describe its potential and limitations.
\end{abstract}

\section{Introduction}

Nicotinamide adenine dinucleotide (NADH/NAD+) is the most important cofactor involved in energy metabolism in live human cells. NADH/NAD+ participates in glycolysis, the citric acid cycle and the mitochondrial respiratory chain, beta-oxidation, reduction of pyruvate to lactate, as well as the modification of RNA together with regulation of transcription. It is also a part of the second messenger system [1,2]. Some examples of NADH involvement in cellular metabolism are pictured in Figure 1.
Nicotinamide adenine dinucleotide exists in two forms: reduced NADH and oxidised NAD+. Both are found in the cytosol, cellular organelles, nucleus and the mitochondria [3]. However, the main site of NADH oxidation to NAD+ are the mitochondria. The architecture of a mitochondrion is outlined in Figure 1: an intermembrane space separates the outer and inner membranes and the mitochondrial matrix with the electron transport chain and genome are contained within said inner membrane [4]. 


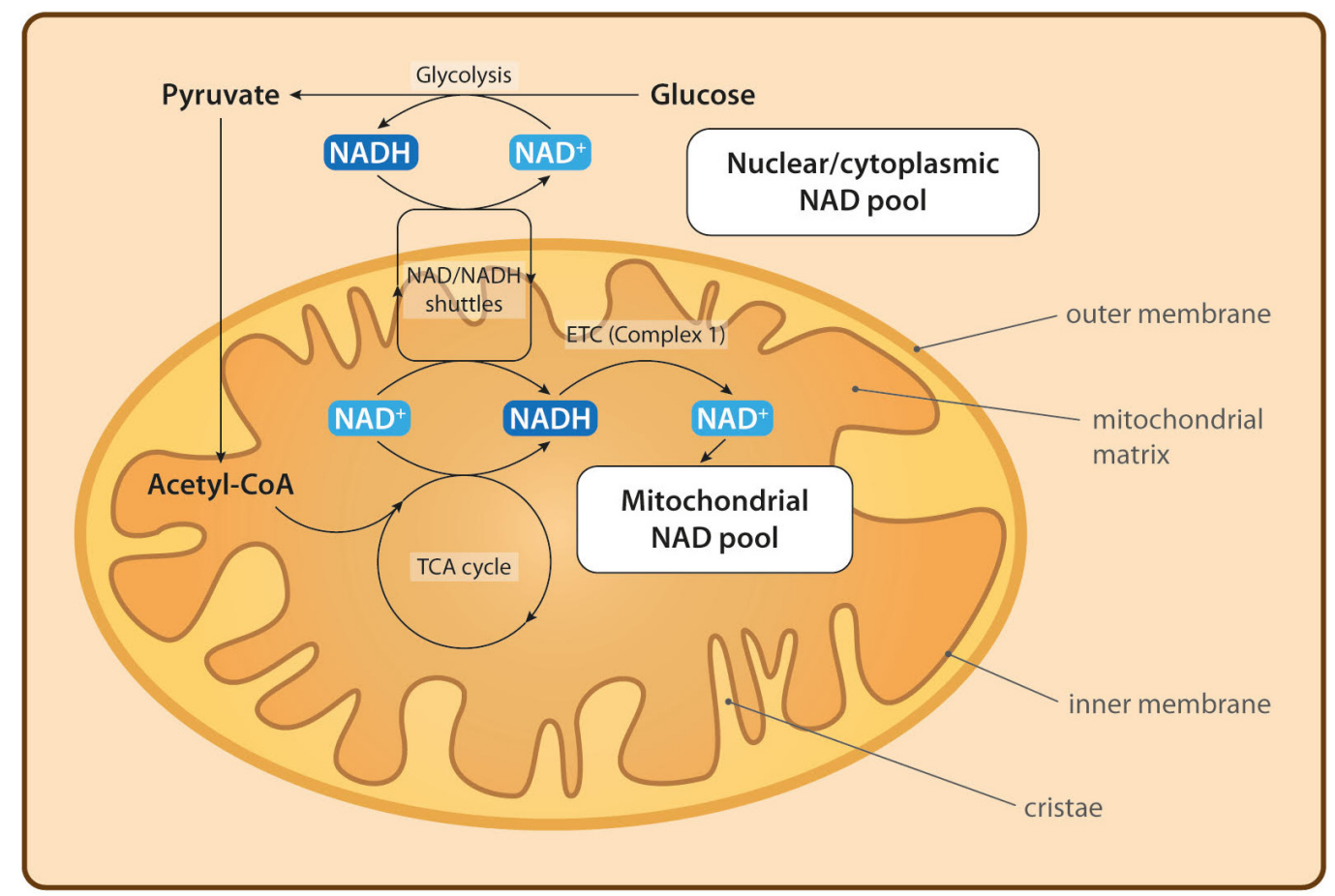

Figure 1. Metabolic pathways of NADH in cytosol and mitochondria. Abbreviations: ETC - electron transport chain; TCA cycle - tricarboxylic acid cycle

The intermembrane space is critical for storing protons involved in ATP production and both creatine kinase and adenine kinase are localised there. Both the outer and inner membranes are impermeable to most metabolites, including NADH. As NADH cannot cross the mitochondrial membranes, the transportation of high energy electrons from this molecule to the electron transport chain involves special reducing equivalents. The malate-aspartate and glycerophosphate cross membrane shuttles are two known pathways which transport reducing equivalents of NADH from cytoplasm to mitochondrial matrix.

The indirect, shuttle-based transportation of high energy electrons from NADH through the shuttling substrates across the mitochondrial membrane occurs only in aerobic conditions. Therefore, during anaerobic conditions (such as ischaemia), NADH produced by glycolysis accumulatesin thecytoplasm, and its reducing equivalents cannot be passed further down to the mitochondrial matrix through the inner membrane. $\mathrm{NADH}$ inside mitochondria cannot be oxidised by Complex I to NAD+ and thus the redox state changes in favour of NADH. Therefore, the amount of NADH may be utilised as a surrogate marker for absolute (hypoxia) or relative (increased metabolism) oxygen deprivation [3].

The NADH content can be measured in several ways. Some of the examples include spectrophotometric, fluorometric $[3,5]$ and bioluminescent enzyme assays [6,7]. Interestingly, exciting NADH with ultraviolet (UV) light in the 320-380 $\mathrm{nm}$ range produces autofluorescent light emission in the $420-480 \mathrm{~nm}$ range with peak intensity at $450-460 \mathrm{~nm}$ - this optical feature has been widely used for measuring NADH concentration or content in solutions, cells and tissues [3].

Chance applied the UV/fluorescence-based method to monitor the NADH amount in cells and tissues or concentration in liquids [8]. The first device that allowed for such measurement was developed in 1954 by Theorell and Nygaard [9], and in 1962 Chance et al. studied NADH content in the brain and kidneys of anaesthetized rats [10]. In 1966 Chance showed that the primary source of $420-480 \mathrm{~nm}$ UV photoemission is the $\mathrm{NADH}$ and not the oxidised NAD+, thus validating this method for NADH quantification $[8,10]$. Since then, the fluorescence method has been commonly used in many in-vivo studies. For instance, Mayevsky et al. studied NADH with this method in rats [11] and humans [12]. 
Mayevsky et al. showed that the majority of 460-nm fluorescence comes from mitochondria with an irrelevant contribution of cytoplasm on human and animal skin models [3]. Dunaev et al. showed that the UV and fluorescent light penetrates only the most superficial skin layers - up to $0.5 \mathrm{~mm}$ in depth - with the majority of photoemission coming from the depth up to $0.3 \mathrm{~mm}$ [13]. Thus, most of the fluorescence comes from the epidermis, which lacks a direct blood supply. Nutrients and oxygen are delivered to the epidermis directly from dermis and via dermal microcirculation [3,13]. Figure 2 outlines the penetration of UV light and the origin of the fluorescence derived from NADH in human skin. sible for the NADH oxidation to NAD+, decreases and then ceases $[15,16]$. As a result NADH accumulates in mitochondria. Restoration of oxygen delivery to mitochondria and its matrix rapidly reverses this process. Complex I activity recovers and NADH is immediately oxidised to NAD+. Therefore, following ischaemia-induced hypoxia, reperfusion induces a rapid decline in NADH concentration $[15,17]$.

The phenomenon of NADH accumulation during ischaemia and its reduction during reperfusion has been used by Piotrowski et al. to measure the dynamic changes in the NADH accumulation using the UV excitement and fluorescent emission method [18]. The method - termed

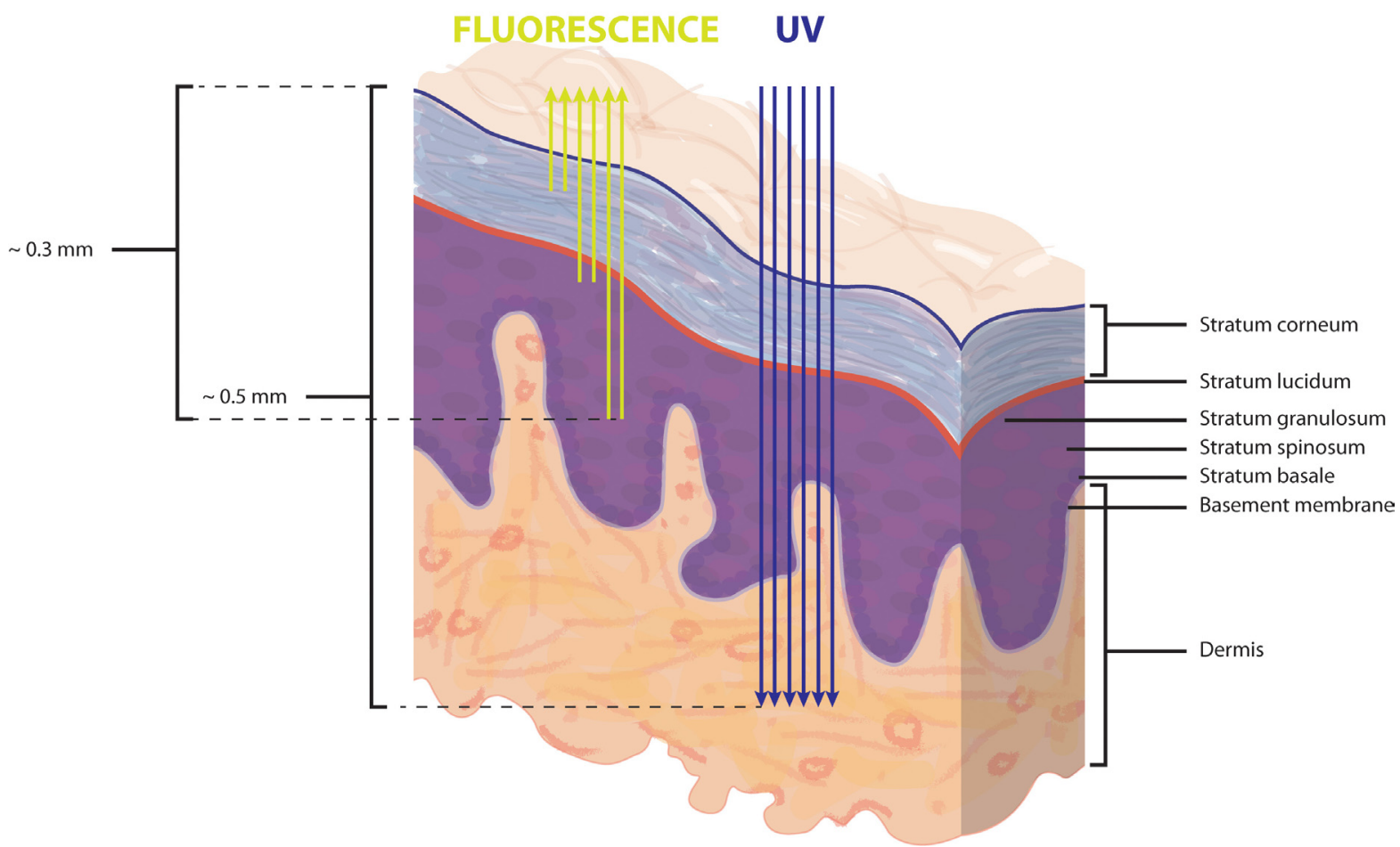

Figure 2. Penetration of the ultraviolet (UV) light through different skin layers and the source of the fluorescent light specific for NADH. Maximum penetration is about $0.5 \mathrm{~mm}$, but the majority of the autofluorescence typical for NADH comes from the depth up to $0.3 \mathrm{~mm}$

Dynamic measurement of skin NADH content during ischaemia and reperfusion challenge Cellular energy production in aerobic conditions depends on oxygen availability. During transient ischaemia, blood flow is ceased, leading to a decrease in oxygen supply. This leads to cellular metabolism switching into the anaerobic mode. The electron transfer through the electron transport chain stops [14], the activity of mitochondrial Complex I (NADH dehydrogenase), respon-
Flow Mediated Skin Fluorescence (FMSF) involves continuous measurement of $460-\mathrm{nm}$ fluorescence during ischaemia and reperfusion challenge. More specifically, the proposed FMSF method studies the dynamic changes in the 460$\mathrm{nm}$ fluorescence after an earlier $340-\mathrm{nm}$ ultraviolet excitation of the human forearm skin during a TIAR. Figure 3 shows a typical curve produced during FMSF plotting the intensity of photo emissions during an ischaemia-reperfusion episode. 
During ischaemia, there is a gradual increase until the plateau of the $460-\mathrm{nm}$ fluorescence intensity. The restoration of blood flow leads to a rapid decline in the strength of this signal (Figure 3) followed by its gradual recovery to the reference values. There are some grossly visible oscillations of the 460-nm fluorescence. Those are present at rest and reperfusion but not during ischaemia [19] (Figure 4). Their nature is unclear and under investigation. The FMSF method is simple, fast and allows for real-time, dynamic and non-invasive measurement. The AngioExpert device (manufactured by Angionica in Lodz, Poland) is currently the only available device employing the FMSF method.

\section{Measurement of the flow-mediated} skin 460-nm fluorescence

To record the FMSF with the AngioExpert device, the forearm of a study participant is immobilised

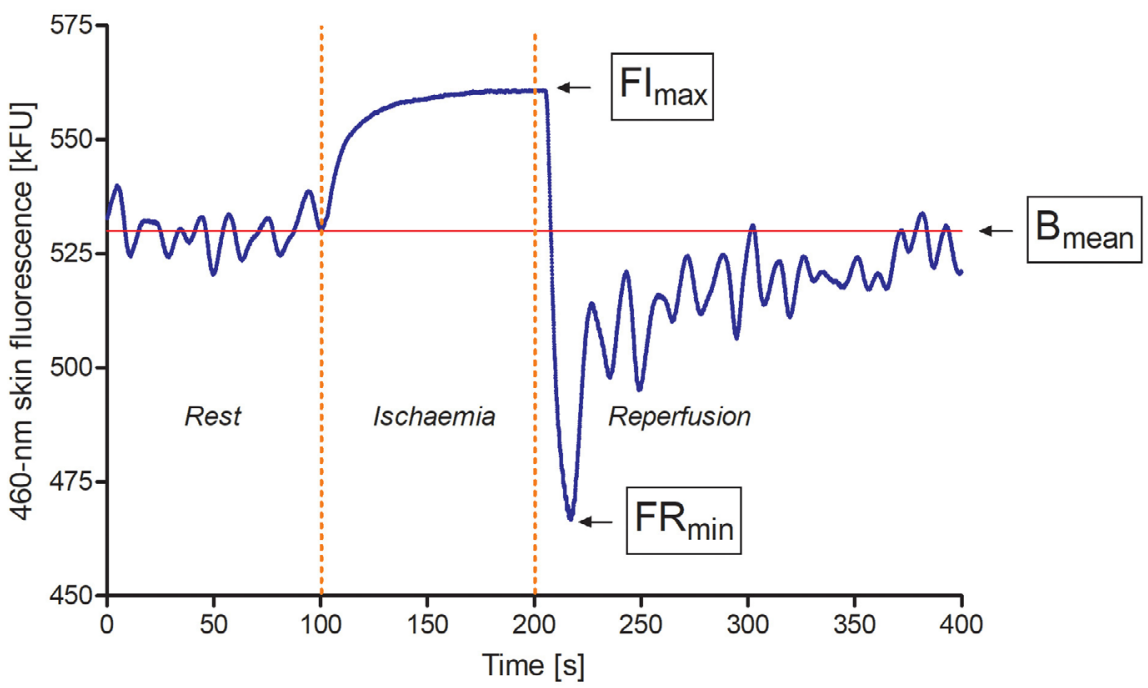

Figure 3. Typical changes of 460-nm forearm skin fluorescence during rest, ischaemia and reperfusion. At rest, NADH content is relatively stable, although some fluctuations are visible. During ischaemia, there is a rapid increase in NADH content. Reperfusion leads to fall of NADH, followed by slow recovery to the baseline level. For the abbreviations, please refer to the main text

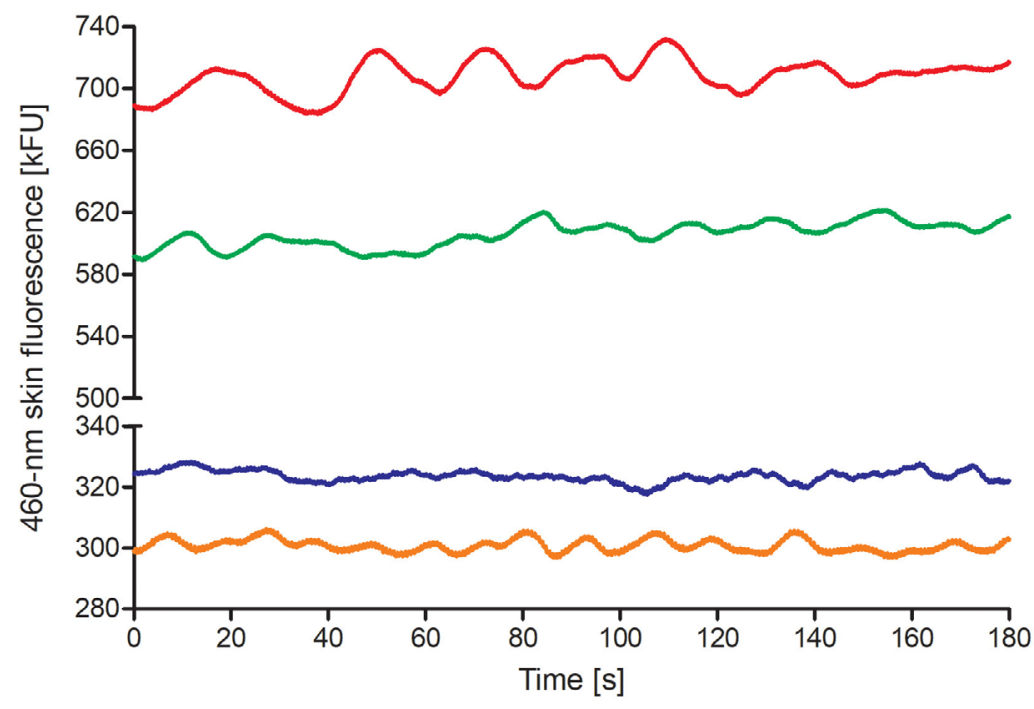

Figure 4. Four samples of the 460-nm fluorescence intensity and oscillations recorded in different young and healthy volunteers resting in a sitting position. There are natural differences in the baseline 460-nm fluorescence intensity between different people, depending for example, on the melatonin amount in the skin. All oscillations of different amplitude and frequency occur during normal blood flow. These oscillations disappear when blood supply is ceased during ischemia (please compare Figure 4 and Figure 6) 
in special support to minimise recording noise. To induce TIAR, a deflated brachial cuff is placed on the studied arm for the baseline recording, and then it is inflated to $60 \mathrm{mmHg}$ above Systolic Blood Pressure (SBP) for at least 100 seconds (in some studies 300 seconds [20]) to induce transient and controlled ischaemia. To allow for reperfusion, the brachial cuff is rapidly and wholly deflated.

The fluorescence data is obtained from a UV emitter-sensor device. The forearm completely covers the UV light emitter and fluorescence sensor. As the UV sensor is sensitive to movement, the study participant is required to remain still, and the forearm support is employed to improve the quality of readings. An example recording of 100 -second ischaemia is shown in Figure 4. This procedure is safe and commonly applied in human studies [21,22], including both studies on healthy volunteers and studies on patients with an active disease process.

To quantify the FMSF response, we have proposed and use the following parameters $[19,21]$ :

, Bmean [kFU] - mean fluorescence at $460 \mathrm{~nm}$ recorded before each ischaemia as the baseline value;

, FImax $[\mathrm{kFU}]$ - the maximal 460-nm fluorescence that increased above the baseline during each controlled forearm ischaemia;

, FRmin [kFU] - the minimal 460-nm fluorescence after decreasing below the baseline during each reperfusion;

, Imax [kFU] - the difference between FImax and Bmean;

, Rmin [kFU] - the difference between Bmean and FRmin;

, IRampl [kFU] - the maximal range of the 460$\mathrm{nm}$ fluorescence change during ischaemia and reperfusion;

- Clmax - Imax/IRampl ratio showing the relative contribution of the NADH increase during ischaemia to the maximal change in NADH during TIAR.

So far, the FMSF method has been applied in several studies, including both healthy people and patients with various diseases. Table 1 summarises all available publications describing this method.

Literature analysis and our current experience helped us identify some limitations of the FMSF method, which we describe below.
Limitations related to the 460-nm fluorescence method of measuring NADH

\section{Skin properties}

Skin parameters vary between individuals and ethnic groups, and it appears that the fluorescence intensity is affected by the melanin content of the skin. The percentage melanin content of the basal layer of the epidermis varies between $1 \%$ and $43 \%$ [23]. The study by Dremin and Dunaev suggests that the fluorescence signal decreases as the skin pigment increases [24]. Thus, comparing the results of skin fluorescence between participants from different ethnic groups at nominal value is inappropriate without appropriate statistical modelling that would account for this confounder. Additionally, the fluorescence signal is affected by epidermis thickness which varies between body sites. Epidermis thickness measured by Robertson and Rees using confocal microscopy differs between $55.6 \mu \mathrm{m}$ (upper back) to $62.5 \mu \mathrm{m}$ (back of the hand) [25]. Therefore, data comparison and pooling can only be attempted with measurements taken at the same body site.

\section{NADH/NAD+ balance}

The 460-nm fluorescence measures only NADH and not NAD+ content [3]. NAD+ does not possess optic properties similar to $\mathrm{NADH}$ and so does not allow for direct quantity measurement. However, in a short period, it is usually assumed that the total amount of NAD (sum of NADH and $\mathrm{NAD+}$ ) remains close to constant [3]. Klein et al. confirmed the assumption in their study on dogs where the entire NAD content remained constant during the first 30 minutes of ischaemia [26]. However, during more extended ischaemia of over 30 minutes, the total NAD content depletes, and the interpretation of NADH/NAD+ becomes less reliable.

\section{Uncertainty about cellular NADH origin}

As already mentioned, NADH is present not only in the mitochondria but also in the cytoplasm and the nucleus. The 460-nm fluorescence measures total tissue or cellular NADH content. However, as shown by Anderson-Engels and Wilson, the $460-\mathrm{nm}$ fluorescence, at least at resting aerobic conditions, comes primarily from mitochon- 
drial NADH $[3,27]$ with negligible input from the cellular NADH. This is supported by many other studies on various tissues $[3,28,29]$. It is therefore assumed that the $460-\mathrm{nm}$ fluorescence informs about the redox state of mitochondrial NADH. It is also uncertain what is the main source of the 460-nm fluorescence increase - NADH from cytoplasm generated by glycolysis or NADH from the mitochondrial matrix as it cannot be oxidised to NAD+ as hypoxia/anoxia stop the function of the electron transport chain. Regardless the processes which have the largest contribution to the $\mathrm{NADH}$ increase during ischaemia, it is more certain that the sudden drop in its content during reperfusion is caused by rapid oxidation of this molecule to NAD+ in the mitochondrial matrix. In other words, the NADH drop during reperfusion appears to be mostly, if not exclusively, related to the function of the electron transport chain. For this reason, the rapid reduction in NADH content during reperfusion is a valuable index of the restoration of mitochondrial function after earlier ischaemia.

\section{Uncertainty about the} mitochondrial pool of NADH

NADH in mitochondria is divided into two pools: free NADH and protein-bound NADH. Proteinbound NADH makes up around $35 \%$ of the total NADH while contributing to almost $80 \%$ of the fluorescence signal [30]. Blinova et al. showed that the binding site of NADH molecules influences the intensity of NADH autofluorescence in mitochondria [31]. When NADH binds to the Complex 1, the NADH fluorescence is enhanced tenfold, but when it binds to other matrix enzymes, such as lactate dehydrogenase, then this fluorescence increases only 1.5-2 fold. The FMSF method does not inform about NADH relocation inside mitochondria.

\section{Spontaneous oscillations of the} 460-nm fluorescence

As already mentioned and shown in Figure 5, the resting $460-\mathrm{nm}$ fluorescence is dynamic, with clearly visible oscillations. Their nature is unknown, they disappear during ischaemia and return, usually with a higher amplitude, during reperfusion. These oscillations are currently investigated by Angionica, i.e. the manufacturer of the AngioExpert device.
Measurement of the skin fluorescence as an index of microvascular function Most of the studies on the post-UV skin 420-480 $\mathrm{nm}$ fluorescence repeatedly show that this method measures NADH content and mitochondrial function $[3,8,10-13,18,19,21,23,24,28-32]$. It is evident that mitochondrial function and oxidation of NADH to NAD+ strictly depend on the blood flow through circulation and supply of oxygen. In other words, less available oxygen impairs mitochondrial function and attenuates NADH oxidation. Mayevsky has suggested that the monitoring of $\mathrm{NADH}$ by the autofluorescence also reflects the role of microvascular circulation $[3,11,12]$. For this reason, it is never definite what the most probable cause of the observed change in NADH skin content - mitochondria, microcirculation or both is? In some studies, the $460-\mathrm{nm}$ fluorescence is only used for measuring the microvascular circulation [22,33-36].

\section{Limitations related to the FMSF method}

Forearm skin as the target body part for studying This method, due to the construction of the measuring table and forearm support, allows measuring the FMSF in the forearm only. Although the 460-nm fluorescence can be measured anywhere in the skin or other tissues [3], the Angioexpert device allows measuring the FMSF signal only using one of two forearms.

\section{Atypical response \\ Typical changes of the FMSF signal occurring during ischaemia and reperfusion in healthy indi- viduals are presented in Figure 4 and Panel $A$ of Figure 5. However, sometimes there are atypical FMSF responses noted in healthy people. Some examples of such atypical FMSF curves are shown in panels $B, C$ and $D$ in Figure 5. \\ Most commonly, the atypical FMSF response is limited to the ischaemic part of the recording. So far, there is no clear explanation for this phe- nomenon.}

Ambiguous and variable duration of the ischaemic challenge

For the FMSF method, the optimal time for ischaemia duration is not established, and differ- 

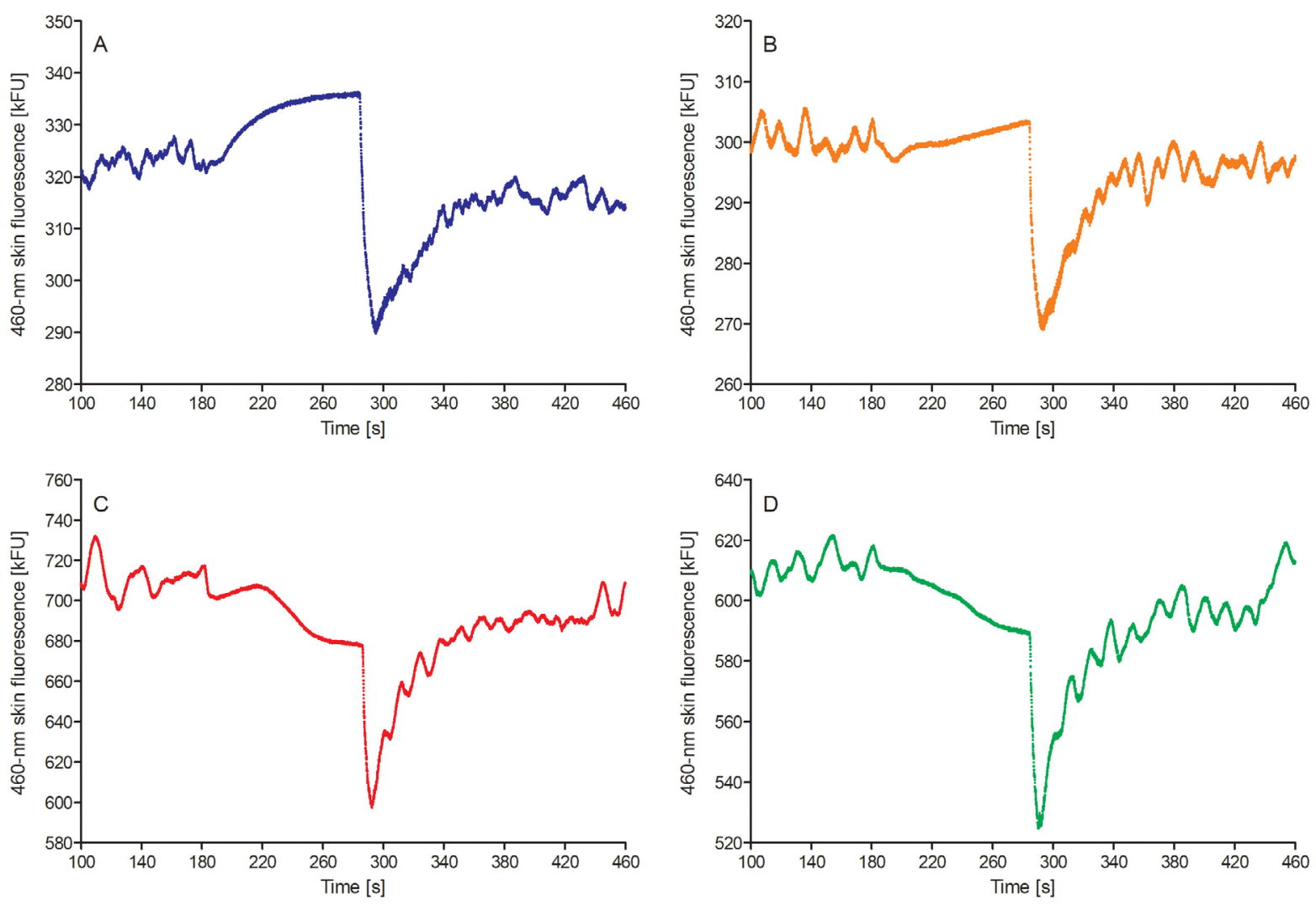

Figure 5. Examples of 460-nm skin fluorescence responses during ischaemia-reperfusion. Graph A represents the typical response, with an increase of FMSF signal during ischemia, its rapid fall during reperfusion, followed by restoration of the fluorescence to the baseline level. Graph B, C and D represent atypical responses found in young, healthy individuals

ent times are applied in various studies ranging from 100 seconds to 300 seconds [20]. A significant factor limiting ischaemia duration is numbness onset in the studied arm and forearm during ischaemia. Some patients may report pain of different severity, usually mild. Most commonly, however, the sensation experienced during the reperfusion phase is described by the participants as a transient feeling of warmth and itching lasting for 15-30 seconds. For these reasons, it is important to inform the participant about the potential uncomfortable symptoms which are, fortunately, short-lasting, tolerable and carry no risk.

\section{Ambiguous interpretation and} terminology of the reperfusion phase

The term proposed by the Angionica for the reperfusion phase was hyperaemia. Undoubtedly, as shown in Figure 6, during the first 20 seconds of reperfusion, there is a transient increase in the blood flow through the microcirculation. How- ever, normalisation of the blood flow to the reference level is much faster than the normalisation of FMSF signal, which takes about 2-5 minutes to recover to the baseline level. It suggests that terming the entire reperfusion phase as "hyperaemia" is not right to the physiological phenomena occurring.

So far, most of the published studies with FMSF employ the prototype AngioExpert device, which is under development. Although there were no significant changes made to the construction, UV light emitter and fluorescent sensor, the proposed parameters used to quantify the FMSF were changing over time. This is a natural consequence of a very young method, and for this reason, there are significant differences in the definitions and names of parameters describing the same FMSF curve. On the other hand, Angionica appears flexible and puts no limits for the use of different descriptors (see Figure 4, compare with studies listed in Table 1). 


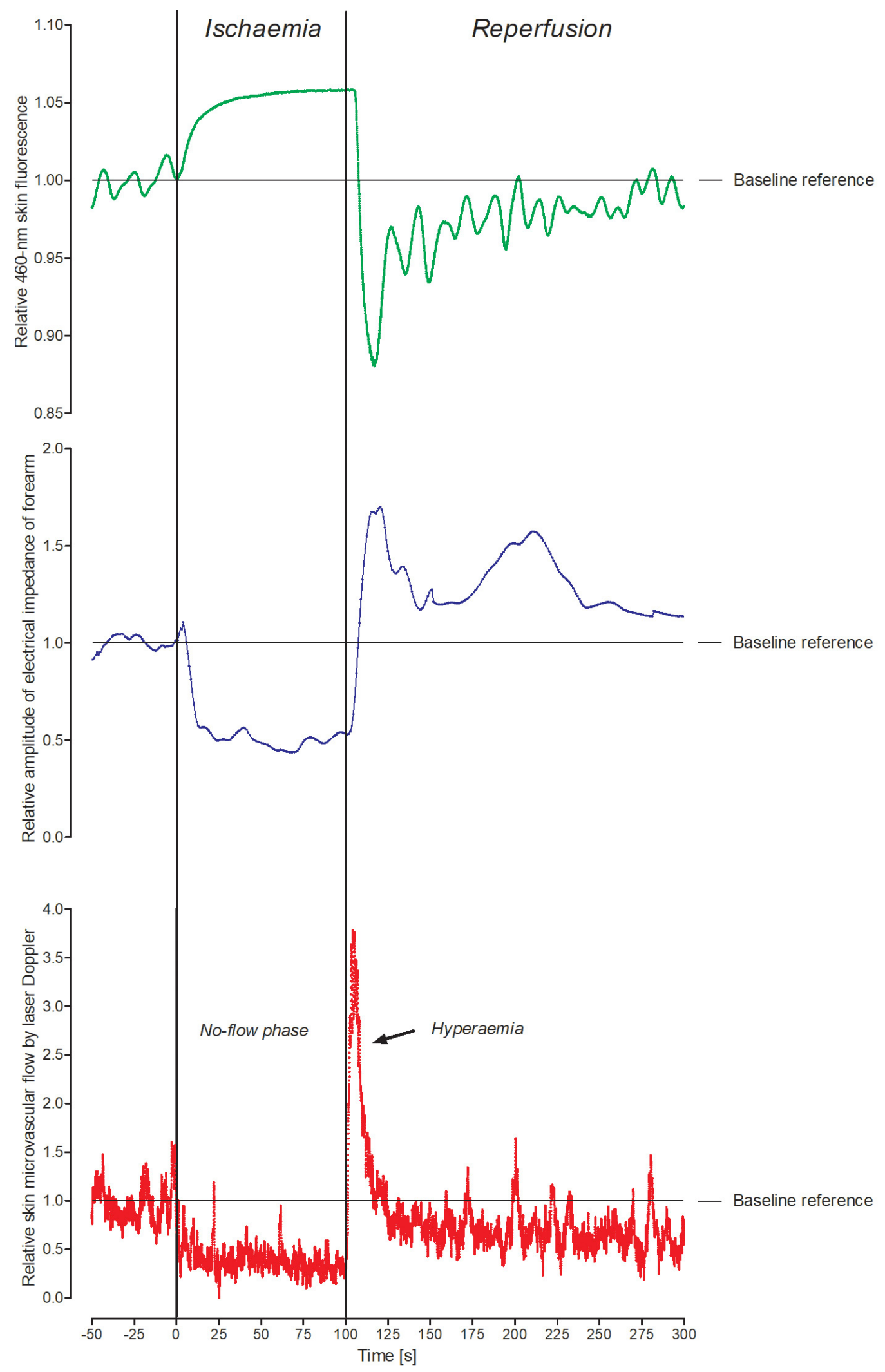

Figure 6. Example of simultaneous recording of FMSF, electrical impedance (showing the amount of water in the forearm) and laser Doppler (presenting the blood flow through skin microcirculation) during ischemia-reperfusion. The signals are synchronised according to the beginning and end of ischaemia. As shown, the dynamics of the changes in all three signals are not identical. It means that the FMSF signal is not a simple derivative of blood flow as assumed by some other authors $[19,21,23,26]$. FMSF is a more complex signal influenced by both NADH metabolism in mitochondria, the function of skin microcirculation and probably some other, yet unknown factors (e.g. water accumulation in the skin) 
Table 1. Summary of studies using the FMSF method

\begin{tabular}{|c|c|c|}
\hline Authors & Studied subjects & Summary \\
\hline $\begin{array}{l}\text { Piotrowski } \\
\text { et al. [22] }\end{array}$ & $\begin{array}{l}11 \text { healthy volunteers and } 11 \text { patients } \\
\text { with cardiovascular diseases }\end{array}$ & $\begin{array}{l}\text { FMSF curves have different characteristics between healthy volunteers and } \\
\text { patients with cardiovascular disease }\end{array}$ \\
\hline $\begin{array}{l}\text { Hellman } \\
\text { et al. [20] }\end{array}$ & $\begin{array}{l}18 \text { healthy volunteers and } 18 \text { patients } \\
\text { with coronary artery disease }\end{array}$ & $\begin{array}{l}\text { Reduction of the value of NADH descriptors during reperfusion in patients } \\
\text { with coronary artery disease compared with healthy subjects. }\end{array}$ \\
\hline $\begin{array}{l}\text { Tarnawska } \\
\text { et al. [24] }\end{array}$ & $\begin{array}{l}28 \text { patients with coronary artery } \\
\text { disease }\end{array}$ & $\begin{array}{l}\text { Ischaemic and reperfusion parts of the FMSF curves are blunted in patients } \\
\text { with advanced coronary artery disease and diabetes. NADH fluorescence in } \\
\text { patients with CAD is associated with plasma endothelial markers. }\end{array}$ \\
\hline $\begin{array}{l}\text { Bugaj } \\
\text { et al. [21] }\end{array}$ & 121 highly trained athletes & $\begin{array}{l}\text { Exercise to exhaustion increases the skin NADH content at rest, during } \\
\text { ischaemia and reperfusion but reduces the magnitude of NADH increase } \\
\text { during ischemia both on men and women. }\end{array}$ \\
\hline $\begin{array}{l}\text { Katarzynska } \\
\text { et al. [25] }\end{array}$ & $\begin{array}{l}31 \text { healthy volunteers and } 40 \text { patients } \\
\text { with type } 1 \text { diabetes (DM1) }\end{array}$ & $\begin{array}{l}\text { The } 460-\mathrm{nm} \text { fluorescence drop during reperfusion is weaker in patients } \\
\text { with type } 1 \text { diabetes than in healthy people. This reperfusion-induced drop } \\
\text { of fluorescence attenuates with age in diabetic patients. }\end{array}$ \\
\hline $\begin{array}{l}\text { Bogaczewicz } \\
\text { et al. [26] }\end{array}$ & $\begin{array}{l}34 \text { healthy volunteers and } 36 \text { patients } \\
\text { with systemic lupus erythematosus }\end{array}$ & $\begin{array}{l}\text { Patients with systemic lupus erythematosus have a reduction restoration of } \\
\text { NADH during reperfusion compared to healthy people. }\end{array}$ \\
\hline $\begin{array}{l}\text { Majewski } \\
\text { et al. [27] }\end{array}$ & $\begin{array}{l}20 \text { healthy volunteers, } 23 \text { patients } \\
\text { with asthma, } 26 \text { patients with chronic } \\
\text { obstructive pulmonary disease } \\
\text { (COPD) }\end{array}$ & $\begin{array}{l}\text { The } 460-\mathrm{nm} \text { fluorescence increase during ischaemia is reduced in patients } \\
\text { with COPD patients compared with healthy people. The } 460-\mathrm{nm} \\
\text { fluorescence drop during reperfusion is weaker in COPD patients compared } \\
\text { to asthma and healthy subjects. }\end{array}$ \\
\hline $\begin{array}{l}\text { Sibrecht } \\
\text { et al. [19] }\end{array}$ & One healthy individual & $\begin{array}{l}\text { Hyperaemic phase (measured by laser Doppler) of post-ischaemic } \\
\text { reperfusion lasts app } 20 \text { seconds while the fluorescence signal during } \\
\text { reperfusion recovers to baseline after over } 200 \text { seconds. Flow-related } \\
\text { changes in the microvascular circulation contribute only to the early phase } \\
\text { of reperfusion part of the FMSF curve. }\end{array}$ \\
\hline $\begin{array}{l}\text { Sibrecht } \\
\text { et al. [28] }\end{array}$ & 99 healthy volunteers & $\begin{array}{l}\text { Post-ischaemic preconditioning reduces NADH skin content and its } \\
\text { increase during the following ischaemia episodes }\end{array}$ \\
\hline $\begin{array}{l}\text { Nizinski } \\
\text { et al. [29] }\end{array}$ & 58 healthy volunteers & $\begin{array}{l}\text { An increased BMI is accompanied by a faster and higher increase of NADH } \\
\text { during ischaemia and a delayed NADH recovery during reperfusion. }\end{array}$ \\
\hline Filberek [30] & 99 healthy volunteers & $\begin{array}{l}\text { Men have more intense skin fluorescence during ischaemia and higher } \\
\text { contribution of ischaemia to whole fluorescence change }\left(\mathrm{Cl}_{\text {max }}\right) \text {. }\end{array}$ \\
\hline
\end{tabular}

\section{Conclusion}

The 460-nm fluorescence intensity reflects the skin NADH content, which is mainly oxidised in mitochondria. However, mitochondrial function strictly depends on the oxygen supply by the skin microcirculation. Therefore it remains uncertain whether the dynamic alterations in this fluorescence recorded by the FMSF during TIAR reflect the function of either mitochondria or microvascular circulation or most probably both.

The FMSF is a unique scientific method to study the skin mitochondrial NADH content and its dynamic changes during transient and controlled ischaemia and reperfusion. This method is non-invasive, allows measuring NADH changes in a real-time and can be applied in many clinical and physiological scenarios. Although the FMSF has some limitations, its non-invasive character and scientific potential seem to merit further investigation. One of the most attractive features of this method is an opportunity to study mitochondrial function and/or microvas- cular circulation during the clinically relevant challenge such as ischaemia and reperfusion. Another interesting feature is that the reduction in the 460-nm fluorescence during the reperfusion reflects the restoration of mitochondrial function after earlier ischaemia. For many reasons, the FMSF appears to have a lot of potential for implementation in physiological, clinical and pharmacological studies.

\section{Acknowledgements}

\section{Conflict of interest statement}

The authors declare no conflict of interest.

\section{Funding sources}

This work was supported by the research grant "Najlepsi z Najlepszych! 2.0" Programme of the Polish Ministry of Science and Higher Education (MNiSW/2017/118/ DIR/NN2 - PIs: GS, PF \& JN), and partially by a projects ANG/ZK/1/2017 (PI: PG) as a part of the project from the European Union from the resources of the European Regional Development Fund under the Smart Growth Operational Program, Grant No. POIR.01.01.0100-0540/15. 


\section{References}

1. Brand MD, Affourtit C, Esteves TC, Green K, Lambert AJ, Miwa S, Pakay JL, Parker N. Mitochondrial superoxide: production, biological effects, and activation of uncoupling proteins. Free Radical Biology and Medicine. 2004 09;37(6):755-67. https://doi. org/10.1016/j.freeradbiomed.2004.05.034

2. Anderson KA, Madsen AS, Olsen CA, Hirschey MD. Metabolic control by sirtuins and other enzymes that sense $\mathrm{NAD}+\mathrm{NADH}$, or their ratio. Biochimica et Biophysica Acta (BBA) - Bioenergetics. 2017 Dec;1858(12):991-8. https://doi.org/10.1016/j.bbabio.2017.09.005

3. Mayevsky A, Rogatsky GG. Mitochondrial function in vivo evaluated by NADH fluorescence: from animal models to human studies. American Journal of Physiology-Cell Physiology. 2007 02;292(2):C615C640. https://doi.org/10.1152/ajpcell.00249.2006

4. Koga Y, Tanaka M, Ohta S, Wei Y. Biochemistry of mitochondria, life and intervention 2010. Biochimica et Biophysica Acta (BBA) - General Subjects. 2012 05;1820(5):551-552. https://doi.org/10.1016/j. bbagen.2012.01.008

5. Marín-García J, Akhmedov AT, Moe GW. Mitochondria in heart failure: the emerging role of mitochondrial dynamics. Heart Failure Reviews. 201206 17;18(4):439-456. https://doi.org/10.1007/s10741012-9330-2

6. Vidugiriene J, Leippe $D$, Sobol M, Vidugiris G, Zhou W, Meisenheimer P, Gautam P, Wennerberg K, Cali JJ. Bioluminescent Cell-Based NAD(P)/NAD(P)H Assays for Rapid Dinucleotide Measurement and Inhibitor Screening. ASSAY and Drug Development Technologies. 2014 Dec;12(9-10):514-526. https://doi. org/10.1089/adt.2014.605

7. Levy B, Ambrosio G, Pries A, Struijker-Boudier $\mathrm{H}$. Microcirculation in Hypertension. Circulation. 200108 07;104(6):735-740. https://doi.org/10.1161/ hc3101.091158

8. Chance B, Cohen P, Jobsis F, Schoener B. Intracellular Oxidation-Reduction States in Vivo: The microfluorometry of pyridine nucleotide gives a continuous measurement of the oxidation state. Science. 1962 Aug 17;137(3529):499-508. https://doi.org/10.1126/ science.137.3529.499

9. Theorell $H$, Nygaard A. Kinetics and equilibria in flavoprotein systems. I. A fluorescence recorder and its application to a study of the dissociation of the old yellow enzyme and its resynthesis from riboflavin phosphate and protein. Acta Chem Scand. 1954,:877-88.

10. Chance B. Mitochondrial NADH redox state, monitoring discovery and deployment in tissue. Methods in Enzymology. 2004;:361-70. https://doi.org/10.1016/ S0076-6879(04)85020-1 PMID 15130749

11. Mayevsky A, Chance B. A New Long-Term Method for the Measurement of NADH Fluorescence in Intact Rat Brain With Chronically Implanted Cannula. Adv Exp Med Biol. 1973;37A:239-44. https://doi. org/10.1007/978-1-4684-3288-6_30 PMID 4378057

12. Mayevsky A, Sonn J, Luger-Hamer M, Nakache R. Real-Time assessment of organ vitality during the transplantation procedure. Transplantation Reviews.
2003 04;17(2):96-116. https://doi.org/10.1016/s0955470x(02)00007-1

13. Dunaev AV, Dremin VV, Zherebtsov EA, Rafailov IE, Litvinova KS, Palmer SG, Stewart NA, Sokolovski SG, Rafailov EU. Individual variability analysis of fluorescence parameters measured in skin with different levels of nutritive blood flow. Medical Engineering \& Physics. 2015 06;37(6):574-583. https://doi. org/10.1016/j.medengphy.2015.03.011

14. Chen Q, Camara AKS, Stowe DF, Hoppel CL, Lesnefsky EJ. Modulation of electron transport protects cardiac mitochondria and decreases myocardial injury during ischemia and reperfusion. American Journal of Physiology-Cell Physiology. 2007 01;292(1):C137C147. https://doi.org/10.1152/ajpcell.00270.2006

15. Riess ML, Camara AKS, Chen Q, Novalija E, Rhodes SS, Stowe DF. Altered NADH and improved function by anesthetic and ischemic preconditioning in guinea pig intact hearts. American Journal of Physiology-Heart and Circulatory Physiology. 2002 07 01;283(1):H53-H60. https://doi.org/10.1152/ ajpheart.01057.2001

16. Lesnefsky EJ, Chen Q, Moghaddas S, Hassan MO, Tandler B, Hoppel CL. Blockade of Electron Transport during Ischemia Protects Cardiac Mitochondria. Journal of Biological Chemistry. 200409 03;279(46):47961-47967. https://doi.org/10.1074/ jbc.m409720200

17. Varadarajan SG, An J, Novalija E, Smart SC, Stowe DF. Changes in $[\mathrm{Na}+] \mathrm{i}$, compartmental [Ca2+], and $\mathrm{NADH}$ with dysfunction after global ischemia in intact hearts. American Journal of Physiology-Heart and Circulatory Physiology. 200101 01;280(1):H280-H293. https://doi.org/10.1152/ ajpheart.2001.280.1.h280

18. Mayevsky A, Chance B. Oxidation-reduction states of $\mathrm{NADH}$ in vivo: From animals to clinical use. Mitochondrion. 2007 09;7(5):330-339. https://doi. org/10.1016/j.mito.2007.05.001

19. Sibrecht G, Bugaj O, Filberek P, Nizinski J, Kusy K, Zielinski J, Guzik P. Flow-Mediated Skin Fluorescence Method for Non-Invasive Measurement of the NADH At $460 \mathrm{Nm}$ - a Possibility To Assess the Mitochondrial Function. Postępy Biologii Komórki. 2017;44(4):333-52.

20. Hellmann M, Tarnawska M, Dudziak M, Dorniak K, Roustit M, Cracowski J. Reproducibility of flow mediated skin fluorescence to assess microvascular function. Microvascular Research. 2017 09;113:6064. https://doi.org/10.1016/j.mvr.2017.05.004

21. Bugaj O, Zieliński J, Kusy K, Kantanista A, Wieliński D, Guzik P. The Effect of Exercise on the Skin Content of the Reduced Form of NAD and Its Response to Transient Ischemia and Reperfusion in Highly Trained Athletes. Frontiers in Physiology. 201905 15;10. https://doi.org/10.3389/fphys.2019.00600

22. Piotrowski L, Urbaniak M, Jedrzejczak B, Marcinek A, Gebicki J. 10.1152/ajpheart.2001.280.1.H280 Note: Flow mediated skin fluorescence-A novel technique for evaluation of cutaneous microcirculation. Review of Scientific Instruments. 2016 03;87(3):036111. https://doi.org/10.1063/1.4945044 
23. Jacques SL. Corrigendum: Optical properties of biological tissues: a review. Physics in Medicine and Biology. 201306 27;58(14):5007-5008. https://doi. org/10.1088/0031-9155/58/14/5007

24. Dremin VV, Dunaev AV. How the melanin concentration in the skin affects the fluorescence-spectroscopy signal formation. Journal of Optical Technology. 201601 01;83(1):43. https://doi.org/10.1364/ jot.83.000043

25. Rees J, Robertson K. Variation in Epidermal Morphology in Human Skin at Different Body Sites as Measured by Reflectance Confocal Microscopy. Acta Dermato Venereologica. 2010;90(4):368-373. https:// doi.org/10.2340/00015555-0875

26. Klein HH, Schaper J, Puschmann S, Nienaber C, Kreuzer $\mathrm{H}$, Schaper W. Loss of canine myocardial nicotinamide adenine dinucleotides determines the transition from reversible to irreversible ischemic damage of myocardial cells. Basic Research in Cardiology. 1981 Nov;76(6):612-621. https://doi.org/10.1007/ bf01908051

27. Andersson-Engels S, Brian C. In vivo fluorescence in clinical oncology: fundamental and practical issues. J Cell Pharmacol. 1992;3:66-79.

28. Nuutinen EM. Subcellular origin of the surface fluorescence of reduced nicotinamide nucleotides in the isolated perfused rat heart. Basic Research in Cardiology. 1984 01;79(1):49-58. https://doi.org/10.1007/ bf01935806

29. Mayevsky A. Brain NADH redox state monitored in vivo by fiber optic surface fluorometry. Brain Research Reviews. 1984 03;7(1):49-68. https://doi. org/10.1016/0165-0173(84)90029-8

30. Blinova K, Carroll S, Bose S, Smirnov AV, Harvey JJ, Knutson JR, Balaban RS. Distribution of Mitochondrial NADH Fluorescence Lifetimes: Steady-State Kinetics of Matrix NADH Interactions. Biochemistry.
2005 02:44(7):2585-2594. https://doi.org/10.1021/ bi0485124

31. Blinova K, Levine RL, Boja ES, Griffiths GL, Shi Z, Ruddy B, Balaban RS. Mitochondrial NADH Fluorescence Is Enhanced by Complex I Binding. Biochemistry. 200809 09;47(36):9636-9645. https://doi. org/10.1021/bi800307y

32. Blacker TS, Duchen MR. Investigating mitochondrial redox state using NADH and NADPH autofluorescence. Free Radical Biology and Medicine. 2016 Nov;100:53-65. https://doi.org/10.1016/j. freeradbiomed.2016.08.010

33. Tarnawska M, Dorniak K, Kaszubowski M, Dudziak M, Hellmann M. A pilot study with flow mediated skin fluorescence: A novel device to assess microvascular endothelial function in coronary artery disease. Cardiology Journal. 2018;25(1):120-7. https://doi. org/10.5603/CJ.a2017.0096 PMID 28840593

34. Katarzynska J, Borkowska A, Czajkowski P, Los A, Szczerbinski L, Milewska-Kranc A, Marcinek A, Kretowski A, Cypryk K, Gebicki J. Flow Mediated Skin Fluorescence technique reveals remarkable effect of age on microcirculation and metabolic regulation in type 1 diabetes. Microvascular Research. 2019 07;124:1924. https://doi.org/10.1016/j.mvr.2019.02.005

35. Bogaczewicz J, Tokarska K, Wozniacka A. Changes of NADH Fluorescence from the Skin of Patients with Systemic Lupus Erythematosus. BioMed Research International. 2019 Dec 24;2019:1-7. https://doi. org/10.1155/2019/5897487

36. Majewski S, Szewczyk K, Białas AJ, MiłkowskaDymanowska J, Kurmanowska Z, Górski P. Assessment of microvascular function in vivo using flow mediated skin fluorescence (FMSF) in patients with obstructive lung diseases: A preliminary study. Microvascular Research. 2020 01;127:103914. https:// doi.org/10.1016/j.mvr.2019.103914 